\title{
Evaluation of the Cultural Proximity Factors Impact on the Mutual Trade Efficiency of the Countries within Eurasian Economic Integration
}

\author{
Veronika Vyazovskaya*, Irina Savelyeva, Oksana Falchenko, Maria Chaikina \\ World Economy and Foreign Economic Activity Department, Ural State University of Economics, Yekaterinburg, \\ 6201142, Russia \\ *Corresponding author. Email: vyazovv@usue.ru
}

\begin{abstract}
The purpose of this scientific paper is to assess the national cultures proximity impact on the effectiveness of regional economic integration in the Eurasian Economic Union (EAEU). To assess the cultural proximity (distance) of the countries, the criteria developed by Hofstede were used and the cultural proximity (distance) of each country in the EAEU was calculated using the formulas developed by Kogut and Singh, which made it possible to assess the cultural proximity of the EAEU countries. The article also assesses the impact of cultural proximity (distance) on the effectiveness of mutual trade between the countries of Eurasian integration using the trade gravity model. Calculations showed that the cultural proximity of the countries of integration does not significantly affect the mutual trade of the EAEU countries. However, the commonality of the language used in the country is the only cultural factor, the presence of which in a pair of trading countries increases trade.
\end{abstract}

Keywords: regional economic integration, integration processes, mutual trade, the EAEU, cultural factors,

cross-cultural interaction, gravity model, cultural proximity of countries, cultural distance

\section{INTRODUCTION}

A significant difference in the EAEU formation from other integration associations is not only the predominance of economic interests, but also political, social, and cultural motives, which consists in an attempt to consolidate the post-Soviet space to jointly solve the problems of socioeconomic development and ensure the security of the member states of the union.

The cultural factor within the framework of regional economic integration can be the basis for predicting whether regional economic integration will move to the next level and whether it will be sustainable. The distance between countries can be estimated not only by the geographical dimension, but also from the standpoint of cultural factors that directly affect the effectiveness of the integration interaction of countries and their mutual trade.

The purpose of this article is to study and assess the impact of countries cultural proximity on the regional economic integration effectiveness. The object of this study is the Eurasian Economic Union. The subject of the study is to assess the impact of the cultural proximity of integrating countries on their mutual trade (export) The objectives of the study are: 1) a theoretical justification of the importance of cultural factors in assessing the effectiveness of regional economic integration; 2) a practical analysis of the influence of the EAEU countries cultural proximity on their mutual trade based on the application of regression analysis.

\subsection{Literature Review}

Classic works devoted to the problems of integration processes, where the essence and evolution of forms of integration were considered, were the studies of B. Balassa [1], J. Viner [2], R. G. Lipsey [3]. A significant contribution to the study of the economic effects of integration were made by S.L. Baier, J.H. Bergstrand[4;5]; R. Baldwin, D. Jaimovich [6]; P. Egger, M. Larch [7]; M. Fugazza, F. Robert-Nicoud [8]; L. Gruber [9]; M.S. Manger [10]; A. Knobel [11].

The analysis of trading effects using the gravity model is presented by studies of P. Egger, D. Nelson [12], H. Vandenbussche, M. Zanardi [13]; J.E. Anderson, E. van Wincoop [14; 15]. The possibilities and problems of using gravity models for the analysis of international and interregional trade flows are described in the works of A.N. Mogilat, V.A. Salnikov [16], M. V. Radionova, A. M. Kulakova [17] A. Shumilov [18].

The analysis of the mutual trade of EAEU member countries using the gravity model is presented in the works of A. Knobel [11], M.A. Baeva [19; 20], I.P. Gurova [21; $22]$, which allows us to approach the development of the concept of Eurasian integration that is in line with the 
interests of the EAEU countries in the field of economic development.

The works of L. Vardomsky [23; 24], I. Andronova [25], Butorin, Zakharov [26] emphasize the uniqueness of the EAEU as an integration project with a powerful economic, geopolitical and ideological background, based on the historical and cultural community of the participating countries.

In recent years, there have been works aimed at the study of cultural factors in the development of integration associations. According to Čuhlová [27], the effective development of integration processes between partner states requires not only geographical proximity, but also similarities in terms of culture, history and ideology. Great importance is attached not only to the presence of cooperative ties, but also to a linguistic community, which provides the basis for successful interaction. The importance of understanding cultural distance in the context of regional integration associations is noted by Colakoglu and Caligiuri [28] T. Zuva and Z. Worku [29] and other authors.

At the same time, the features of cultural interaction within the framework and the influence of cultural factors on trade flows of EAEU member countries did not receive sufficient research attention.

\section{METHODS AND RESULTS}

\subsection{Hypothesis}

We have formulated the following research hypotheses: $\mathrm{H} 1$ : cultural proximity and the general historical past of the countries participating in the integration association positively affect the volume of mutual trade;

H0: the cultural proximity and the general historical past of the countries participating in the integration association do not affect the volume of mutual trade.

\subsection{Gravity Model Description}

As an empirical tool for assessing the influence of the cultural factor on the mutual trade dynamics between the partner countries of the integration union, the gravity model using the R-Studio software was used.

To build the model the Authors used statistical data for the period from 1995 to 2015. CEPII, the French Center for Advanced Studies and International Information, as an recognized worldwide independent research center in the field of international trade. Additionally, data from the Eurasian Economic Commission for 2016-2018 were ised in the sample. Statistics of trade flows between the EAEU countries is presented by the United Nations Comtrade database.

The loglinear form of the intuitive gravity model has the following form:

$$
\begin{gathered}
\log X_{i j}=c+b_{1} \log G D P_{i}+b_{2} \log G D P_{j} \\
+b_{3} \log \tau_{i j}+e_{i j}, \\
\log \tau_{i j}=\log \left(\text { distance }_{i j}\right),
\end{gathered}
$$

where $X_{i j}$ - export from country $i$ to country $j$, $G D P$ - gross domestic product of a country,

$\tau_{i j}$ - trade costs between two countries,

distance $_{i j}$ - geographical distance between a pair of countries, as an explanatory variable for trade costs,

$e_{i j}$ - random error

The value $c$ is the regression constant, and the indicators $b_{1,2,3}$ are the coefficients that need to be estimated.

Modern researchers (Anderson, J., and E. Van Wincoop, 2003) [14] as alternative measures of size also use the population, area of the country, GDP per capita, and the following factors include the determinants of trade costs: customs tariffs; transportation costs; membership in currency, trade, and political unions, exchange rate volatility, language barriers, colonial ties, a common religion, geographic variables, and others.

\subsection{Step-by-Step Process of Gravity Modeling}

The first step in studying the relationships that underlie the gravity model is to study the correlation between the variables. In total, the downloaded data set contains 58 indicators (columns) and 440 observations (rows) generated between 1995 and 2018 .

The second step is to calculate the correlation coefficient for a number of explanatory variables: trade, distance, GDP of the exporting country and GDP of the importing country. In this paper, we expanded the list of indicators and additionally investigated the degree of correlation of the population indicators of trading countries (Figure 1).

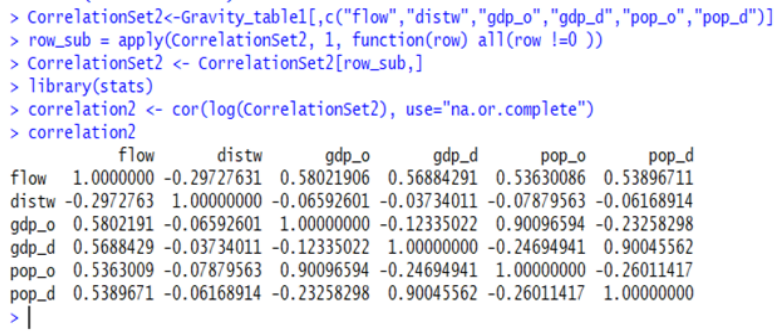

Figure 1 Correlations of the studied data

The correlation coefficients of interest to us are contained in the off-diagonal elements of the matrix. We see that trade volumes and indicators of GDP, population and the area of the Union countries are strongly correlated, and that the correlation coefficient is positive and almost the same for GDP of both exporters and importers. This conclusion confirms the basic idea of the gravity model that larger countries tend to trade more. At the same time, for trade indicators and the distance between the countries participating in the Union, we can observe the opposite trend: pairs of countries that are further apart from each other trade less. 
To represent the same information in graphical form, use the plot command. Figure 3 shows a graph reflecting the dependence of mutual trade on the total economic mass of the EAEU member countries (their total GDP). The scatter plot shows a clear positive relationship between the two variables; the line of best fit (regression line) is directed up. Thus, this graph also confirms the basic idea of the gravity model of the economy that larger pairs of countries tend to trade more.

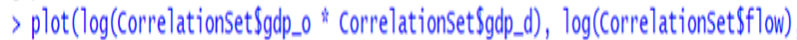 type $=$ "p", $x\rceil a b=$ "In_gdp_both", ylab = "In_trade") $>$ abline( $($ m(log $($ CorrelationsetSflow) $) \log ($ CorrelationsetSgdp_o *} $+$

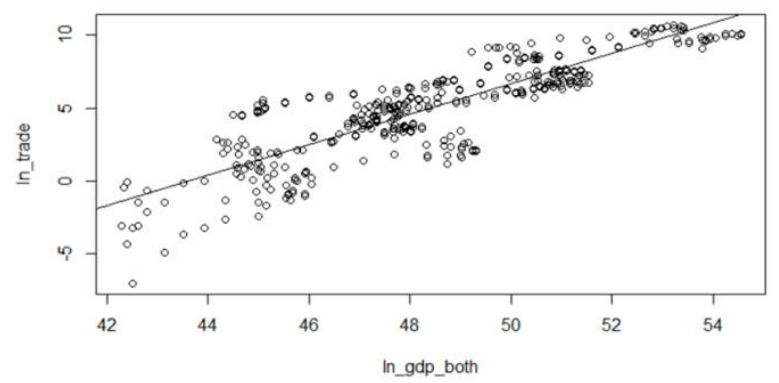

Figure 2 Scatter chart and regression line for trade relative to total GDP

However, when evaluating the basic gravity model, the following limitations must be taken into account. Firstly, the basic gravity model considers the economic union apart, regardless of the influence of countries and trade agreements located outside it. Secondly, a proportional decrease in trade costs on all routes within the model leads to a proportional increase in trade in the relevant areas.

The third step was to assess the impact of cultural proximity on the dynamics of mutual trade of the EAEU countries. To calculate the cultural distance of the EAEU countries, the model of B. Kogut and G. Singh (1988) [30] was chosen, and the model of G. Hofstede (2001) [31], including an analysis of 6 cultural dimensions, was used as a methodological basis for the study. Since the study can be considered a pilot for the Authors, only the first 4 Hofstede indexes were taken to build the model. Within the framework of this typology, each country was assigned a score in four cultural aspects: the distance of power, individualism, masculinity, and the perception of uncertainty. Based on the estimates, the cultural distance of the EAEU countries was calculated. The measure of cultural distance can be obtained from the calculations developed by B. Kogut and G. Singh (1988) [30] using the cultural dimensions of Hofstede [31].

The index is based on the deviation of each of the cultural dimensions of country $i$ from the country of interest $j$. The formula thus obtained is:

$$
C D_{j}=\frac{1}{N}\left[\sum_{i=1}^{4} \frac{\left(I_{i j}-I_{i A_{i}}\right)^{2}}{V_{i}}\right]
$$

where $C D j-$ cultural distance between country $j$ and the average value of the measurement assessment,

Iij - assessment of country $j$ by $i$ cultural dimension,

$I_{A i j}$ - the average score of countries in this dimension,

$\mathrm{N}$ - number of cultural dimensions;

$V i$ - measurement variance:

$$
D=\frac{\sum(x-\overline{\bar{x}})^{2}}{n}
$$

The final assessment of the cultural distance of regional economic integration is as follows:

$$
C D=\frac{\sum_{j=1}^{n} C D_{j}}{n}
$$

where $C D$ - cultural distance of regional economic integration,

$n$ - number of countries in regional economic integration Visualization of the cultural distance of countries in regional economic integration gives an understanding of which countries in regional economic integration are compatible from a cultural point of view and which are not (Table 1).

\begin{tabular}{|c|c|c|c|c|c|}
\hline $\begin{array}{l}\text { Indicator } \\
\text { Country }\end{array}$ & PD & Ind & $\mathrm{M}$ & $\mathrm{PU}$ & CD \\
\hline RU & 93 & 39 & 36 & 95 & 0,67 \\
\hline ARM & 98 & 32 & 59 & 102 & 0,91 \\
\hline BEL & 89 & 42 & 36 & 92 & 1,90 \\
\hline KAZ & 94 & 36 & 55 & 98 & $\mathbf{0 , 1 7}$ \\
\hline KYR & 100 & 30 & 51 & 104 & 1,36 \\
\hline MV & 94,8 & 35,8 & 47,4 & 98,2 & 1 \\
\hline $\mathrm{D}$ & 14,96 & 19,36 & 93,04 & 19,36 & \\
\hline \multicolumn{6}{|c|}{$\begin{array}{l}\text { Detailed explanation of abbreviations: RU - Russia, } \\
\text { ARM - Armenia, BEL - Belarus, KAZ - Kazakhstan, } \\
\text { KYR - Kyrgyzstan, MV - Mean value, D -Dispersion; } \\
\text { PD - Power distance, Ind - Individualism, M - } \\
\text { Masculinity, PU - Perception of uncertainty, CD - } \\
\text { Cultural distance }\end{array}$} \\
\hline
\end{tabular}

Table 1 Estimated values of the EAEU countries' cultural distance

Belarus and Kyrgyzstan are markedly distinguished from a cultural point of view from all members of the Union.

We will reveal the relationship between the cultural distance of countries and economic indicators in the framework of regional integration.

The main econometric problem that needs to be solved during the assessment of the gravity of the countries of the integration association is the assessment of unknown bparameters of the log-linear model. The main method for solving this problem is the Ordinary Least Squares (OLS) method, which is the econometric equivalent of the lines 
of best fit used previously to demonstrate the relationship between trade and GDP.

Since when constructing the gravity model in $\mathrm{R}$ we use the natural logarithm for several variables, this means that zero and absent values should not be included in the test population.

In addition to distance, we include a number of other observable trade costs as control variables. In particular, we include the following dummy variables equal to one:

- for countries that have a common land border (contig),

- for countries that have a common official language (comlang_off),

- for countries that had a common colonizer (comcol).

According to the basic assumptions of the standard international trade theory, a pair of countries having a common border reduces exchange costs, increasing mutual trade flows, and the historical existence of two countries within the same colonial state and the presence of a common official language reduce the uncertainty of interaction.

The indicator of the total currency in a pair of the studied countries was excluded from the model due to the lack of variation.

The results of the assessment of the gravity model are presented in the Figure 3.

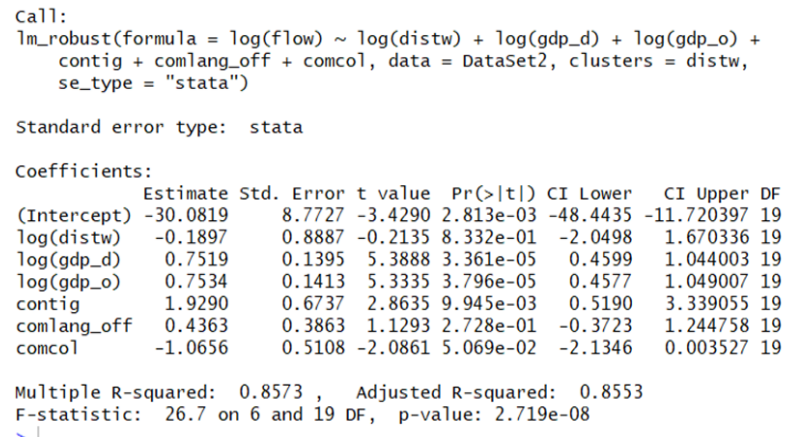

Figure 3 Values and statistical significance of the coefficients of the gravity model of the Eurasian Economic Union in $\mathrm{R}$

\section{RESULTS INTERPRETATION AND DISCUSSION}

Based on the estimates obtained, the following conclusions can be drawn:

Firstly, the gravity model is well suited for the interpretation of the studied data. The determination coefficient of model $\mathrm{R}^{2}$ is 0.86 . This means that explanatory variables account for more than $86 \%$ of observed changes in trade. This figure will increase as additional variables are added to the model.

The second evaluation of the obtained model effectiveness is Student's t-value, which refers to one of the most developed and widely used statistical methods. The deviation range of the null hypothesis for the Student criterion is determined by a pre-accepted level of significance (for example, $\alpha=0.05$ ) and the number of degrees of freedom.

The P-value determines how likely it is to obtain a tcriterion equal to or greater than the real value that we calculated from the available sample data. If this probability turns out to be less than the previously accepted significance level ( $\mathrm{p}<0.05$ ), we have the right to reject the hypothesis being tested. In this case, $\mathrm{p}$-value has a rating of less than $1 \%$. This rejects the null hypothesis at $1 \%$.

Next, we need to carefully consider the estimated coefficients and their corresponding t-tests. Regarding GDP indicators, we see that the GDP of both importers and exporters is positively related to trade: an increase in GDP of exporters or importers by $1 \%$ leads to an increase in trade within the EAEU by about $0.75 \%$, and this effect is statistically significant at level $1 \%$ (p-value in the fifth column is less than 0.01 ).

The country's distance factor coefficient, in contrast, is negative. However, it should be noted that this indicator is not statistically significant for assessing trade within the Eurasian Economic Union. This means that the volume of trade flows within the EAEU is more independent of the distance between the participating countries. This conclusion is consistent with the fact that the trade in goods in the separately considered EAEU is not directly related to transportation costs, since the distance between pairs of countries remains unchanged, and Russia, Belarus and Kazakhstan are the EAEU main driving force, which reduces the geographical distance influence as a trade costs source.

All of the remaining geographic and historical variables except the general colonizer have the positive coefficients. The presence of a common official language is also not statistically significant for this model, because p-value exceeds $5 \%$.

At the same time, the dummy variables influence can be estimated as follows. For example, the EAEU countries that have a common land border trade almost 6 times more than those that do not have it $(\exp [1.9]-1=5.8)$. An unexpected result is that the presence of a common historical colonizer among the pairs of the EAEU member countries adversely affects trade flows (exp [-1.06] - $1=$ $0.65)$. Thus, dummy variables can be quantified in much the same way as quantitative, although the calculation in this case will be different.

For a more detailed analysis and verification of the hypothesis about the significance of the countries cultural proximity to trade, we introduced additional independent variables in the model: quantitative variables (such as, population of the importer (pop_d) and exporter (pop_o) and dummy variables (equal to one) (such as, for countries that have a common religion (comrelig); for couples of countries, more than $9 \%$ of the population of which speak the same language (comlang_ethno)).

Figure 4 shows the results of the assessment of the gravity model taking into account the newly introduced variables. 
Table 2 Evaluation results of the EAEU gravity model

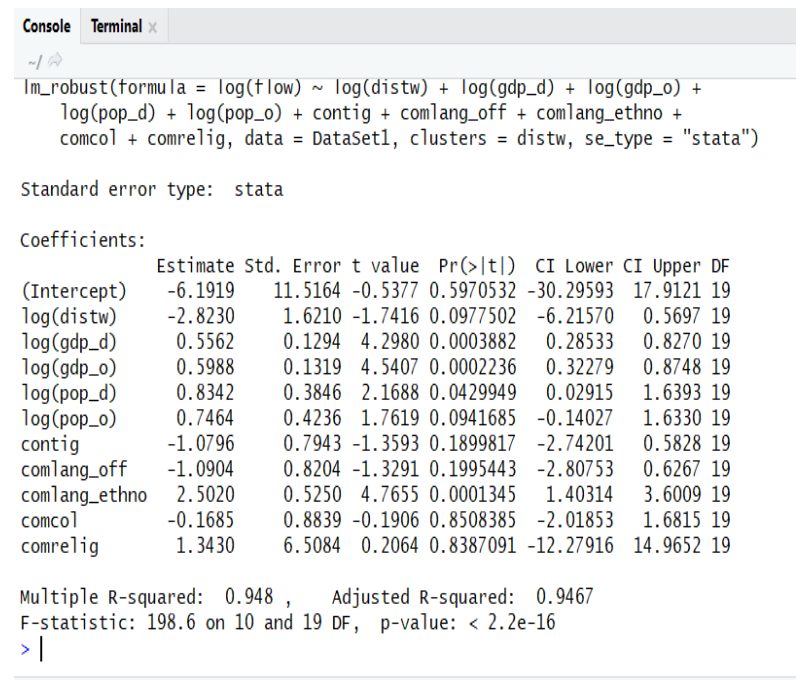

Figure 4 Values and statistical significance of the coefficients of the expanded EAEU gravity model in $\mathrm{R}$

An increase in the number of studied coefficients naturally increases the explanatory power of the model. So, the dispersion index R2 increased to 0.94 compared to 0.86 in the model with the basic set of variables under consideration. The p-value estimate also reflects the statistical significance of the model and has a value of less than $1 \%$.

When considering the updated results of the model, there are significant differences between the models in the significance of such an indicator as the total land border, in the extended model, the p-value for this variable exceeds $5 \%$, which makes it statistically insignificant to determine the volume of trade flows within the EAEU. The significance of indicators such as distance, a common official language, and a common historical colonialist are also rejected. The assessment of GDP indicators has not changed significantly.

Also, to assess the mutual trade of the EAEU countries, the population of the country of the importer is of particular importance. This dependence can be defined as positive, an increase of $1 \%$ in the population stimulates the trade flows growth by $0.8 \%$, which corresponds to a regular increase in demand of the importing country.

The commonality of language is of great importance for establishing integration ties in the EAEU. The language commonality is determined not by the official states' language, but by the presence of a population speaking the same language in the country. Religion community is not a statistically significant indicator in the assessment of trade flows, although it has a positive value.

Below is a summary table of the results obtained during the assessment of the gravity model, and their interpretation (Table 2).

\begin{tabular}{|c|c|c|}
\hline Hypothesis & $\begin{array}{l}\text { Confirmation } \\
\text { of Hypothesis }\end{array}$ & Results \\
\hline $\begin{array}{l}\text { Hypothesis } \mathrm{H} 1 \\
\text { Cultural } \\
\text { proximity } \\
\text { contributes to } \\
\text { the economic } \\
\text { integration of the } \\
\text { EAEU. }\end{array}$ & $\begin{array}{l}\text { Hypothesis } \\
\text { partially } \\
\text { confirmed } \\
1 . \text { The } \\
\text { presence in a } \\
\text { pair of } \\
\text { countries of } \\
\text { common } \\
\text { language } \\
\text { groups } \\
\text { increases } \\
\text { mutual trade } \\
\text { flows. } \\
2 . \text { The } \\
\text { common } \\
\text { religion of } \\
\text { trading } \\
\text { countries is not } \\
\text { statistically } \\
\text { significant. } \\
\text { 3. The general } \\
\text { historical past } \\
\text { does not affect } \\
\text { trade flows } \\
\text { within the } \\
\text { Union. }\end{array}$ & $\begin{array}{l}\text { The EAEU internal } \\
\text { trade is practically } \\
\text { not affected by } \\
\text { indicators of the } \\
\text { region's cultural } \\
\text { integration. The } \\
\text { commonality of the } \\
\text { language used in the } \\
\text { country is the only } \\
\text { cultural factor, the } \\
\text { presence of which in } \\
\text { a pair of trading } \\
\text { countries increases } \\
\text { trade. This trend is } \\
\text { associated with a } \\
\text { reduction in the } \\
\text { uncertainty of trade } \\
\text { interaction and a } \\
\text { corresponding } \\
\text { reduction in } \\
\text { transaction costs of } \\
\text { information search, } \\
\text { communication and } \\
\text { their translation. }\end{array}$ \\
\hline
\end{tabular}

Thus, the estimates obtained as a result of the analysis of the EAEU gravity model do not fully reflect the dependencies defined in scientific studies on this topic. These discrepancies can be caused by a small number of countries in the EAEU, which noticeably distorts the data set under study, reducing the total number of observations taking into account the specifics of the studied integration association.

\section{CONCLUSION}

1) The study assessed the cultural proximity (distance) level using the countries of the Eurasian Economic Union as an example, which led to the conclusion that which countries in regional economic integration are culturally compatible and which are not. Belarus and Kyrgyzstan stand out substantially from all EAEU countries.

2) The results of the regression analysis partially refuted the hypothesis that cultural proximity favors the EAEU economic integration. The EAEU internal trade is practically not affected by indicators of the cultural integration of the region, with the exception of the factor of a single language. 
[13] H. Vandenbussche, M. Zanardi, The Chilling Effects of Antidumping Law Proliferation, in: European Economic Review, 54, 2010, pp. 760-777.

[14] J.E. Anderson, E. van Wincoop, Gravity with Gravitas: A Solution to the Border Puzzle, in: American Economic Review, vol. 93, no. 1, 2003, pp. 170-192. DOI: https://doi.org/10.1257/000282803321455214.

[15] J.E. Anderson, E. van Wincoop, Trade Costs, in: Journal of Economic Literature, vol. 42, 2004, pp. 691751. DOI: https://doi.org/10.1257/0022051042177649.

[16] A.N. Mogilat, V.A. Salnikov, Trade Effects Estimation for the Case of Eurasian Economic Space Countries: Application of Regional Gravity Model. in: Journal of the New Economic Association, 3, 27, 2015, pp. 80-108.

[17] M. V. Radionova, A. M. Kulakova, Modeling of Mutual Commodity Trade Between Countries (a Case Study of The Eurasian Economic Union Member States per Industry), in: Financial Analytics: Science and experience, vol. 34, 2015, pp. 41-54.

[18] A. Shumilov, Estimating Gravity Models of International Trade: A Survey of Methods, in: HSE Economic Journal, vol. 21, no 2, 2017, pp. 224-250.

[19] A.Yu. Knobel, M.A. Baeva, Protective Measures in Integration Agreements and Their Impact on Mutual Trade and Trade with Third Countries: Features of Russia and the Countries of the Eurasian Economic Union), in: SSRN Electronic Journal, 2017, DOI: https://dx.doi.org/10.2139/ssrn.2981764

[8] M. Fugazza, F. Robert-Nicoud, The 'Emulator Effect' of the Uruguay Round on US Regionalism (February 2010), CEPR Discussion Paper No. DP7703. Available at SSRN: https://ssrn.com/abstract=1559659

[9] L. Gruber, Ruling the World: Power Politics and the Rise of Supranational Institutions, Princeton University Press, Princeton, NJ, 2000.

[10] M.S. Manger, Investing in Protection: The Politics of Preferential Trade Agreements between North and South, Cambridge University Press, Cambridge, 2009.

[11] A. Knobel, Eurasian Economic Union: Prospects and Challenges for Development, in: Voprosy Ekonomiki, No. 3, 2015, pp. 87-108. DOI: https://doi.org/10.32609/0042-8736-2015-3-87-108

[12] P. Egger, D. Nelson, How Bad Is Antidumping? Evidence from Panel Data, in: The Review of Economics and Statistics, vol. 93, 2011, pp.1374-1390. DOI: https://dx.doi.org/10.2139/ssrn.978461
[20] M.A. Baeva, Application of Measures to Protect the Domestic Market in Integration Associations in Relation to Partners in Association and in Relation to Third Countries, in: Russian Journal of Entrepreneurship, vol.17, no 24, 2016, pp. 3549-3560. DOI: https://doi.org/10.18334/rp.17.24.37204

[21] I.P. Gurova, Theoretical Model of the Trade Integration in the CiS Region. in: Voprosy Ekonomiki [Economic Issue], 2014, no. 1, pp. 130-143. DOI: https://doi.org/10.32609/0042-8736-2014-1-130-143.

[22] I.P. Gurova, Multidimensional Model of the Eurasian Economic Integration, in: Spatial Economics, vol. 1, 2016, pp. 14-29. DOI: https://doi.org/10.14530/se.2016.1.014-029.

[23] L. Vardomsky, Eurasian integration and the Great Eurasian Partnership, in: Russia and the New States of 
[28] S. Colakoglu, P. Caligiuri, Cultural distance, expatriate staffing and subsidiary performance: The case of US subsidiaries of multinational corporations, in: The international journal of human resource management, vol.19, issue 2, 2008, pp. 223-239.

[29] T. Zuva, Z. Worku, Cultural Differences of Countries Within a Regional Economic Integration and Their Impact on Stakeholders, in: International Journal of Business and Management Studies, vol.8, no 2, 2016.

[30] B. Kogut, H. Singh, The Effect of National Culture on the Choice of Entry Mode, in: Journal of International Business Studies, vol. 19, 1988, pp. 411432. DOI:

https://doi.org/10.1057/palgrave.jibs.8490394

[31] G. Hofstede, Culture's Consequences: Comparing Values, Behaviors, Institutions, and Organizations Across Nations, Second Edition, Sage Publications, Inc, 2001. 